American Journal of Applied Sciences 8 (9): 918-922, 2011

ISSN 1546-9239

(C) 2011 Science Publications

\title{
Modeling Malaysia's Energy System: Some Preliminary Results
}

\author{
Ahmad Mohd. Yusof \\ School of Economics, Faculty of Economics and Management, \\ University Kebangsaan Malaysia, 43650 Bangi Selangor, Malaysia
}

\begin{abstract}
Problem statement: The current dynamic and fragile world energy environment necessitates the development of new energy model that solely caters to analyze Malaysia's energy scenarios. Approach: The model is a network flow model that traces the flow of energy carriers from its sources (import and mining) through some conversion and transformation processes for the production of energy products to final destinations (energy demand sectors). The integration to the economic sectors is done exogeneously by specifying the annual sectoral energy demand levels. The model in turn optimizes the energy variables for a specified objective function to meet those demands. Results: By minimizing the inter temporal petroleum product imports for the crude oil system the annual extraction level of Tapis blend is projected at 579600 barrels per day. The aggregate demand for petroleum products is projected to grow at $2.1 \%$ year $^{-1}$ while motor gasoline and diesel constitute 42 and $38 \%$ of the petroleum products demands mix respectively over the 5 year planning period. Petroleum products import is expected to grow at $6.0 \%$ year $^{-1}$. Conclusion: The preliminary results indicate that the model performs as expected. Thus other types of energy carriers such as natural gas, coal and biomass will be added to the energy system for the overall development of Malaysia energy model.
\end{abstract}

Key words: Energy modeling, Linear Programming (LP), petroleum products, gasoline, scenario, kerosene, endogenously, methodology, Wien Automatic System Planning Package (WASP), Model for Analysis of Energy Demand (MAED)

\section{INTRODUCTION}

Energy models developed by international institutions specifically address national and international issues surrounding the current energy environment. In particular, the first world oil crisis of 1973-1974 had prompted many countries to review the existing models and develop new models in an attempt to study the impact of oil prices hike to the economy. Various types of models were developed with varying structures and objectives that range from single fuel to multi-fuel models linking to the economic sectors either through exogenously specifying the energy demand or endogenously computing from economic models (Mohamed and Lee, 2006; Jebaraj and Iniyan, 2006; Kannan and Strachan, 2009). Malaysia's involvement in adopting world energy models dated as early as 1980's. Models such as Wien Automatic System Planning Package (WASP), Energy and Power Evaluation Program (ENPEP), Long Range Energy Alternatives Planning System (LEAP), Market Allocation (MARKAL) and Model for Analysis of Energy Demand (MAED) were used, but with the exception of WASP (used by the power sector), the other models suffer serious limitations and weaknesses in analyzing Malaysia energy scenarios. This is due primarily to data insufficiency and mismatch between model structure and local energy system. Thus the model gave unreasonable energy projections that Malaysia could not tolerate. In addition there is insufficient number of local modeling experts who can come up with good solution. Thus, the objective of this study is to report preliminary findings on the optimization of the recently developed crude oil system supply module in meeting endogenously sectoral petroleum products demands. The choice of Linear Programming (LP) technique allows us to perform the 'what if' analysis which is an essence of scenario stimulation studies (Koen and Morales, 2004; Contaldi et al., 2007). Furthermore a LP model allows us to add (delete) any energy system to (from) the model, without undergoing much structural changes to the model. As an example, Malaysia is proposing to use nuclear energy by year 2025 and thus this energy system could be included in the model at later stage of its usage.

\section{MATERIALS AND METHODS}

Energy policy modeling should be viewed in the context of energy policy analysis which entails an option to meet energy needs of a particular society. 
Am. J. Applied Sci., 8 (9): 918-922, 2011

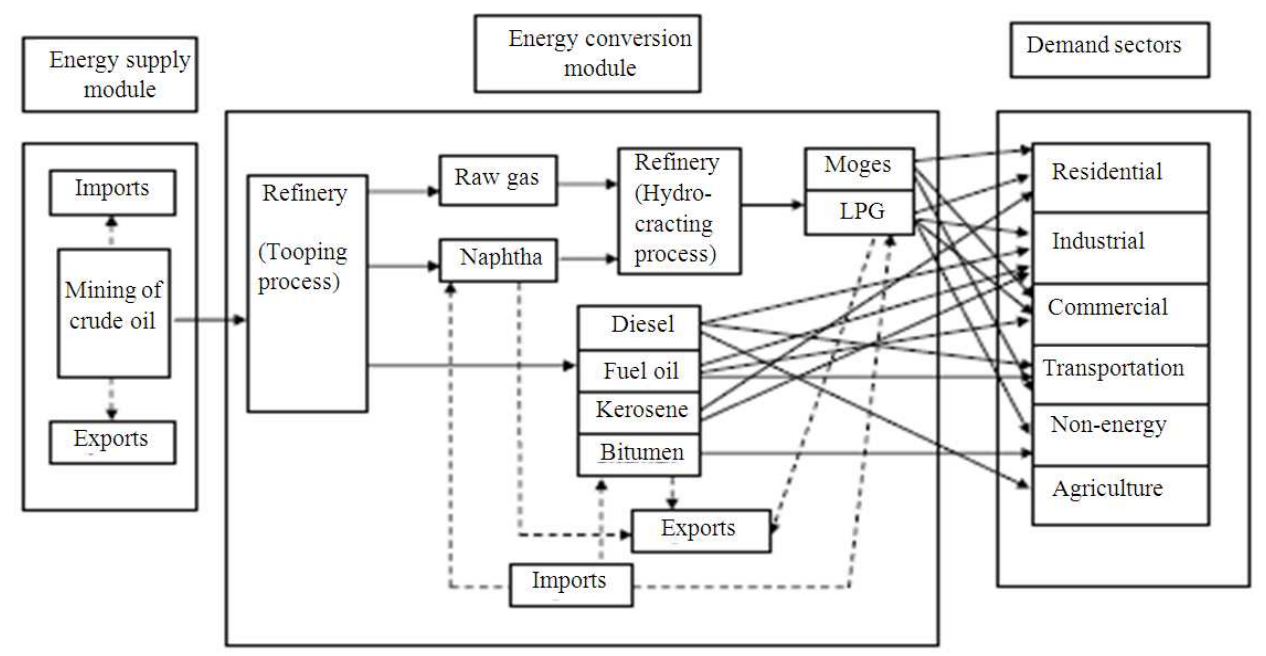

Fig. 1: The Framework of the Malaysia energy system

The consequences of policy option, choices of particular energy resources and policy research analysis (decision making) are some of the pertinent issues raised in policy analysis which might be challenging. However, energy models can provide effective tools in energy policy analysis. The use of a model can reflect complex system in an understandable form. Besides helping to organize large amount of data a model also provide a consistent framework for scenario analysis. In general a model is a simplified representation or abstraction of some aspects of the real world. It describes the system in term of its components, variables, parameters, internal and external relationship. Thus a model should be able to provide a framework for organizing data and assessing the impact of changes in system variables and parameters. Since model building begins with addressing specific questions or hypothesis relating to the national and international issues, no single model can answer all questions related to energy without the use of other sub models embedded within the overall energy model. Based on the world energy models and in particular the Energy Flow Optimization Model (EFOM) and the MARKAL model the crude oil system could be viewed as an energy flow network from its natural resources (mining and imports) undergoing some conversion and transformation processes to produce several energy products which further distributed to other economic sectors (Reddy et al., 1995; Zonooz et al., 2009; Chen et al., 2007; Pietrapertosa et al., 2003). As demand for these products increase, the need for the system to increase the production of crude oil to fulfill the demands also increases. The schematic/flowchart representation of crude oil system is given in Fig. 1.
Crude oil (Tapis Blend) is extracted from offshore wells and some of this is exported while different types of crude oil are imported from other countries. This process is illustrated in the energy supply module. The crude oil will go through to the energy conversion module where it would go through various processing and energy conversions processors before distributed its final petroleum products to the economic and energy demand sectors for final consumption. The demand sectors in Malaysia are categorically classified as residential, commercial, transportation, agriculture, industrial and non-energy. Other crude types such as Bintulu, Miri Light, Dulang and Labuan containing low sulfur content will be added to the system at a later stage of the model development.

Based on the configuration of the model illustrated in Fig. 1, the following equations are developed to run the model.

Extraction to refinery: Equation 1 represents the amount of crude oil from extraction and imports sent to the refinery for the first process called topping. $t$ in the equation stands for a particular time period while $i$ represents different types of crude oil while $\mathrm{R}(\mathrm{MIN}, \mathrm{t}, \mathrm{i})$, $\mathrm{R}(\mathrm{IMP}, \mathrm{t}, \mathrm{i}), \mathrm{R}(\mathrm{EXP}, \mathrm{t}, \mathrm{i})$ are $\mathrm{P}(\mathrm{TOP}, \mathrm{t}, \mathrm{i})$ are decision variables which represents the process of extraction, import, export of crude oil and the process of topping respectively. Coefficient i(TOP,t,i) represents the input coefficient to the topping process.

$\mathrm{R}(\mathrm{MIN}, \mathrm{t}, \mathrm{i})-\mathrm{R}(\mathrm{IMP}, \mathrm{t}, \mathrm{i}) \geq \mathrm{i}(\mathrm{TOP}, \mathrm{t}, \mathrm{i})$
$\mathrm{P}(\mathrm{TOP}, \mathrm{i}, \mathrm{t})+\mathrm{R}(\mathrm{EXP}, \mathrm{t}, \mathrm{i})$

where, $\mathrm{i} \in\{$ Tapis Blend $\}$ and $\mathrm{t} \in\{1,2,3,4,5\}$ 
Topping to hydro cracking: The output of the topping process namely naphtha, raw gas, diesel, raw kerosene, fuel oil and raw bitumen are constrained by their respective output coefficients, o(TOP,t,i). Naphtha and raw gas have to undergo further transformation process of hydro cracking for the production of motor gasoline and LPG respectively. This are represented by Eq. 2:

$$
\begin{gathered}
o(\text { TOP }, \mathrm{t}, \mathrm{i}) \mathrm{P}(\mathrm{TOP}, \mathrm{t}, \mathrm{i})+\mathrm{R}(\mathrm{IMP}, \mathrm{t}, \mathrm{i}) \geq \mathrm{i}(\mathrm{HYD}, \mathrm{t}, \mathrm{i}) \\
\mathrm{P}(\mathrm{HYD}, \mathrm{t}, \mathrm{i})+\mathrm{R}(\mathrm{EXP}, \mathrm{t}, \mathrm{i})
\end{gathered}
$$

where, $i \in\{$ raw gas and naphtha $\}$ and $j \in\{$ motor gasoline and LPG

Equation 2 expresses the process of hydro cracking for the two outputs from topping process. Naphtha is also exported (imported) if the need arises. The outcomes of hydro cracking processes are motor gasoline and LPG. P(HYD,t,i) in the equation is the process of hydro cracking.

Petroleum products to demand sectors: The third component is the distribution of petroleum products to the demand sectors. The output from refinery is distributed to the relevant demand sectors which are represented in Eq. 3. SEL $(t, i, j)$ is the process of selling petroleum products $\mathrm{i}$ to demand sectors $\mathrm{j}$ :

$$
\begin{gathered}
\mathrm{o}(\text { TOP }, \mathrm{t}, \mathrm{i}) \mathrm{P}(\mathrm{TOP}, \mathrm{t}, \mathrm{i})+\mathrm{R}(\mathrm{IMP}, \mathrm{t}, \mathrm{i}) \geq \mathrm{i}(\mathrm{SEL}, \mathrm{t}, \mathrm{i}) \\
\operatorname{SEL}(\mathrm{t}, \mathrm{i}, \mathrm{j})+\mathrm{R}(\mathrm{EXP}, \mathrm{t}, \mathrm{i})
\end{gathered}
$$

Equation 4 is the output to selling of demand of petroleum product to its demand sectors respectively:

$\mathrm{i}(\mathrm{DEM}, \mathrm{t}, \mathrm{i}) \operatorname{DEM}(\mathrm{t}, \mathrm{i}, \mathrm{j}) \geq$

$o(\operatorname{SEL}, \mathrm{t}, \mathrm{i}) \operatorname{SEL}(\mathrm{t}, \mathrm{i}, \mathrm{j})$

The model's constraints consist of crude oil reserves and the capacity of both types of refineries. These constraints are expressed respectively as Eq. 5 and 6.

\section{Reserve constraint:}

$$
\sum_{\mathrm{i}} \sum_{\mathrm{t}} \mathrm{R}(\mathrm{MIN}, \mathrm{t}, \mathrm{i}) \leq \mathrm{R}(\mathrm{MIN}, \mathrm{i})
$$

where, $\mathrm{i}$ equals to crude types and $\mathrm{R}(\mathrm{MIN}, \mathrm{i})$ is the reserve of crude oil (limitation on imports of crude type i).

\section{Refinery capacity constraint:}

$$
\begin{aligned}
& \mathrm{P}(\mathrm{TOP}, \mathrm{t})=\sum_{\mathrm{i}} \sum_{\mathrm{t}} \mathrm{P}(\mathrm{TOP}, \mathrm{t}, \mathrm{i}) \\
& \mathrm{P}(\mathrm{HYD}, \mathrm{t})=\sum_{\mathrm{i}} \sum_{\mathrm{t}} \mathrm{P}(\mathrm{HYD}, \mathrm{t}, \mathrm{i})
\end{aligned}
$$

Several objective functions can be formulated to optimize the model. At this junction, the objective function used is the minimization of the imports of the petroleum products that is:

$\min \sum_{\mathrm{i}} \sum_{\mathrm{t}} \mathrm{R}(\mathrm{IMP}, \mathrm{t}, \mathrm{i})$

where, $\mathrm{i} \in$ \{petroleum products $\}$.

Based on the structure of the model, equations are generated and optimized using LINGO (LP software). For $\mathrm{t}=5$ the model consists of 205 variables, 150 constraints and requires 131 iterations to arrive at an optimal solutions.

\section{RESULTS}

At this stage of model development the primary interest is to make sure that the model runs as expected and produces consistent behavior of the model parameters. In this study, extraction behavior, sectoral demand for petroleum products and imports of petroleum products will be highlighted.

Extraction behavior of crude oil: The extraction level of Tapis Blend crude oil is projected at 1034.6 Peta Joules (PJ) which is the same throughout the 5 time period. This is equivalent to an extraction level of 579600 barrels per day (b/d). No export of crude oil is made.

Demand for petroleum products: The demand for petroleum products is given by Table 1 . The total aggregate demand for petroleum products at $\mathrm{t}=1$ stood at $3241.14 \mathrm{PJ}$ increased to $3604.89 \mathrm{PJ}$ at $\mathrm{t}=5$ with an annual increment of $2.1 \%$ over the staid period. The residential demand for LPG at $\mathrm{t}=1$ stood at $165.71 \mathrm{PJ}$ increased to $184.759 \mathrm{PJ}$ at $\mathrm{t}=5$. This is equivalent to $1.8 \%$ per year. Needless to say the growth of LPG demand in commercial and industrial sectors stood up at the same percentage point. An increase of $3.5 \%$ over the period of 5 years is recorded for the demand for motor gasoline in the transportation sector which is at 1367.7PJ at $\mathrm{t}=1$ and increased to $1536.9 \mathrm{PJ}$ at $\mathrm{t}=5$. Demands for other products namely diesel, fuel oil and bitumen can be found in Table 1. They show increase in demand over the period of 5 years with a reasonable growth rate. 
Am. J. Applied Sci., 8 (9): 918-922, 2011

Table 1: Demand for Petroleum Products (PJ)

\begin{tabular}{|c|c|c|c|c|c|c|}
\hline \multirow{2}{*}{$\begin{array}{l}\text { Petroleum } \\
\text { Products }\end{array}$} & \multirow[b]{2}{*}{ Sector } & \multicolumn{5}{|l|}{ Time } \\
\hline & & 1 & 2 & 3 & 4 & 5 \\
\hline Liquefied & Residential & 165.716000 & 170.476000 & 175.238100 & 179.999100 & 184.759000 \\
\hline Petroleum & Commercial & 110.507800 & 113.683100 & 116.857600 & 120.032500 & 123.207800 \\
\hline Gas (LPG) & Industrial & 49.716000 & 51.145000 & 52.572700 & 54.001000 & 55.430200 \\
\hline Motor gasoline & Transportation & 1367.786000 & 1387.577000 & 1437.368000 & 1487.159000 & 1536.950000 \\
\hline \multirow[t]{2}{*}{ Kerosene } & Residential & 2.456072 & 2.103463 & 1.751143 & 1.398852 & 1.046325 \\
\hline & Industrial & 1.842390 & 1.578229 & 1.313779 & 1.049306 & 0.785057 \\
\hline \multirow[t]{3}{*}{ Diesel } & Industrial & 487.607900 & 501.051700 & 513.935900 & 527.099900 & 540.565700 \\
\hline & Transportation & 755.115500 & 775.936800 & 795.887200 & 816.273100 & 837.128800 \\
\hline & Agriculture & 12.086990 & 11.698020 & 12.739620 & 13.065930 & 12.620550 \\
\hline \multirow[t]{3}{*}{ Fuel oil } & Commercial & 154.085700 & 157.457600 & 160.821000 & 164.176600 & 167.556000 \\
\hline & Industrial & 101.118000 & 103.313400 & 105.530100 & 107.740100 & 109.939300 \\
\hline & Transportation & 2.408676 & 2.468993 & 2.516399 & 2.566417 & 2.627340 \\
\hline Bitumen & Non- energy & 30.688210 & 31.084330 & 31.480460 & 31.876580 & 32.272710 \\
\hline Total & & 3241.140000 & 3309.570000 & 3408.010000 & 3506.430000 & 3604.890000 \\
\hline
\end{tabular}

Table 2: Petroleum product mix (\%)

\begin{tabular}{|c|c|c|c|c|c|}
\hline \multirow[b]{2}{*}{ Petroleum products } & \multicolumn{5}{|l|}{ Time } \\
\hline & 1 & 2 & 3 & 4 & 5 \\
\hline $\begin{array}{l}\text { Liquefied Petroleum } \\
\text { Gas (LPG) }\end{array}$ & 10.060 & 10.130 & 10.110 & 10.100 & 10.080 \\
\hline Motor gasoline & 42.200 & 41.930 & 42.180 & 42.410 & 42.640 \\
\hline Kerosene & 0.130 & 0.110 & 0.090 & 0.070 & 0.050 \\
\hline Diesel & 38.720 & 38.940 & 38.810 & 38.680 & 38.570 \\
\hline Fuel oil & 7.950 & 7.950 & 7.890 & 7.830 & 7.770 \\
\hline Bitumen & 0.940 & 0.940 & 0.920 & 0.910 & 0.890 \\
\hline
\end{tabular}

Table 3: Imports of Petroleum Products (PJ)

\begin{tabular}{|c|c|c|c|c|}
\hline \multirow[b]{2}{*}{ Diesel } & \multicolumn{4}{|c|}{ Petroleum products } \\
\hline & Fuel Oil & LPG & Motor gasoline & Total \\
\hline 794.3288 & 179.2518 & 342.5123 & 1235.311 & 2551.40 \\
\hline 828.9375 & 184.8583 & 352.3527 & 1391.627 & 2757.77 \\
\hline 862.0989 & 190.4854 & 362.1932 & 1441.549 & 2856.33 \\
\hline 895.984 & 196.1225 & 180.8708 & 1491.514 & 2764.49 \\
\hline 930.6497 & 201.7396 & 381.8740 & 1541.435 & 3455.70 \\
\hline
\end{tabular}

Table 2 shows the petroleum products mix over the 5 year period planning horizon. At $t=1$ LPG constitutes $10 \%$ of the petroleum products mix and remains steadily at that level until $\mathrm{t}=5$. A moderate increase in motor gasoline share is observed at $42.2 \%$ at $\mathrm{t}=1$ to $42.6 \%$ at $\mathrm{t}=5$. Diesel demand mix of petroleum products at $\mathrm{t}=1$ stood at $28.7 \%$ and remains around that level until $\mathrm{t}=5$.

Imports of petroleum products: The model also computes the imports of petroleum products which are shown in Table 3. At $\mathrm{t}=1$ the total petroleum products imports stood at 2551.4PJ increased to $3055.7 \mathrm{PJ}$ at $\mathrm{t}=5$. This is equivalent to $6.0 \%$ annual growth rate. Imports of diesel and fuel oil, LPG and motor gasoline show an increasing trend while the imports of other products are at zero level. Diesel imports stood at 794.3PJ at $\mathrm{t}=1$ increased to $930.64 \mathrm{PJ}$ at $\mathrm{t}=5$. This is equivalent $3.1 \%$ of growth rate. The same growth rate is observed for import of LPG, the imports of motor gasoline however increased from 1235.3PJ at $\mathrm{t}=1$ to $1541.43 \mathrm{PJ}$ at $\mathrm{t}=5$ which represents an annual growth rate of $4.5 \%$.

\section{DISCUSSION}

The constant extraction level of crude oil obtained from the model is due to the restriction on the refinery capacity. Had the refinery capacity been increased more extractions as well as the exports are expected. The decreasing trend for the demand for kerosene both in the residential sectors is the reflection of the current energy scenario in Malaysia where kerosene demand is declining over time due to the prosperous economic growth over the past few years. The overall petroleum products mix also closely reflects the current petroleum products mix in Malaysia. The behavior of the extraction level, demand for petroleum products as well as imports of petroleum products shows a steady increasing trend pattern while the bang-bang solution earlier discovered had been eliminated. This is due to the proper choice of the objective function. Thus in view of the above results the performance of the model in analyzing the Malaysian energy scenarios shows a promising prospect.

\section{CONCLUSION}

Inspired by this performance further research on the model development will focus on adding more types of crude oil in the system. This will include Malaysian heavy crude (Bintulu Crude) and imported crude (Dar Blend). Upon satisfactory completion of the crude oil system supply module more energy types namely natural gas, coal, renewable energy (hydro and biomass) should be added in the final development of the energy model. As the needs arise, nuclear energy may be added to the system scheduled for the year 
2025. It is the model's modest aim to provide an integrated energy tool that can be used for future energy planning and study in Malaysia.

\section{REFERENCES}

Chen, W., Z. Wu, J. He, P. Gao and S. Xu, 2007. Carbon emission control strategies for China: A comparative study with partial and general equilibrium versions of the China MARKAL model. Energy, 32: 59-72. DOI: 10.1016/J.energy.2006.01.018

Contaldi, M., F. Gracceva and G. Tosato, 2007. Evaluation of green-certificates policies using the MARKAL-MACRO-Italy model. Energy Policy, 35: 797-808. DOI: 10.1016/J.enpol.2006.03.011

Jebaraj, S. and S. Iniyan, 2006. A review of energy models. Renew. Sustain. Energy Rev., 10: 281311. DOI: 10.1016/j.rser.2004.09.004

Kannan, R. and N. Strachan, 2009. Modelling the UK residential energy sector under long-term decarbonisation scenarios: Comparison between energy systems and sectoral modelling approaches. Applied Energy, 86: 416-428. DOI: 10.1016/J.APENERGY.2008.08.005
Koen, E.L. and S.R. Morales, 2004. Response from a MARKAL technology model to the EMF scenario assumptions, Energy Econ., 26: 655-674. DOI: 10.1016/J.eneco.2004.04.032

Mohamed, A.R. and K.T. Lee., 2006. Energy for sustainable development in Malaysia: Energy policy and alternative energy. Energy Policy, 34: 2388-2397. DOI: 10.1016/J.ENPOL.2005.04.003

Pietrapertosa, F., C. Cosmi, M. Macchiato, G. Marmo and M. Salvia, 2003. Comprehensive modelling for approaching the Kyoto targets on a local scale. Renew. Sustain. Energy Rev., 7: 249-270. DOI: 10.1016/S1364-0321(03)00041-8

Reddy, A.K.N., A. D'sa, G.D. Sumithra and P. Balachandra, 1995. Integrated energy planning: Part I. The DEFENDUS methodology. Energy Sustain. Dev., 2: 15-26. DOI: 10.1016/S09730826(08)60132-5

Zonooz, M.R.F., Z.M. Nopiah, A.M. Yusof and K. Sopian, 2009. A review of MARKAL energy modeling. Eu. J. Sci. Res., 26: 356-361. 